\title{
Refractory esophagopleural fistula post-lobectomy successfully treated by endoscopic submucosal dissection and over-the-scope clip
}

Acquired esophagopleural fistulas are rare adverse events of pneumonectomy and occur in 0.2 to $1 \%$ of cases [1].

The operative treatment of esophagopleural fistulas includes esophagostomy, gastrostomy, possibly local drainage, or thoracotomy and radical operation [2,3] with high morbidity and mortality. Reports of endoscopic closure of such large post-operative fistulas are rare or very expansive devices like the Amplatzer atrial septal closure device are used [4]. Endoscopic submucosal dissection (ESD) achieved closure of fistulas of different etiologies and thus represents a hopefully low-invasive solution [5].

We present the case of a 68-year-old patient who underwent a middle lobectomy for lung cancer complicated with a large esophagopleural fistula on day 8 with purulent pleurisy and right lung abscess. First of all, a 3-month derivation with an esophageal metal stent was attempted but failed. Then, drainage of the fistula with a Kehr's drain (thoracic approach) failed to improve sepsis. A few months later, once the fistula orifice was less inflammatory, the patient was referred to our unit for closure of the orifice using ESD with a clip-and-line traction for the deepest removal possible of the scarring mucosa in the fistula tract ( $\triangleright$ Fig. 1, $>$ Fig. 2, $\triangleright$ Video 1). Then we closed the fistula orifice with an overthe-scope clip (OTSC) placed on the submucosa. In order to protect the ESD, a covering esophageal stent was dropped at the end of the procedure. Six weeks later when the stent was removed, the OTSC clip was already unfixed and the fistula had completely healed without leakage.

ESD followed by OTSC closure and a covering esophageal stent appears to be an effective choice to achieve endoscopic closure of an esophagopleural fistula owing to its non-invasiveness and low morbidity. It should be fully considered among other treatments, even if its

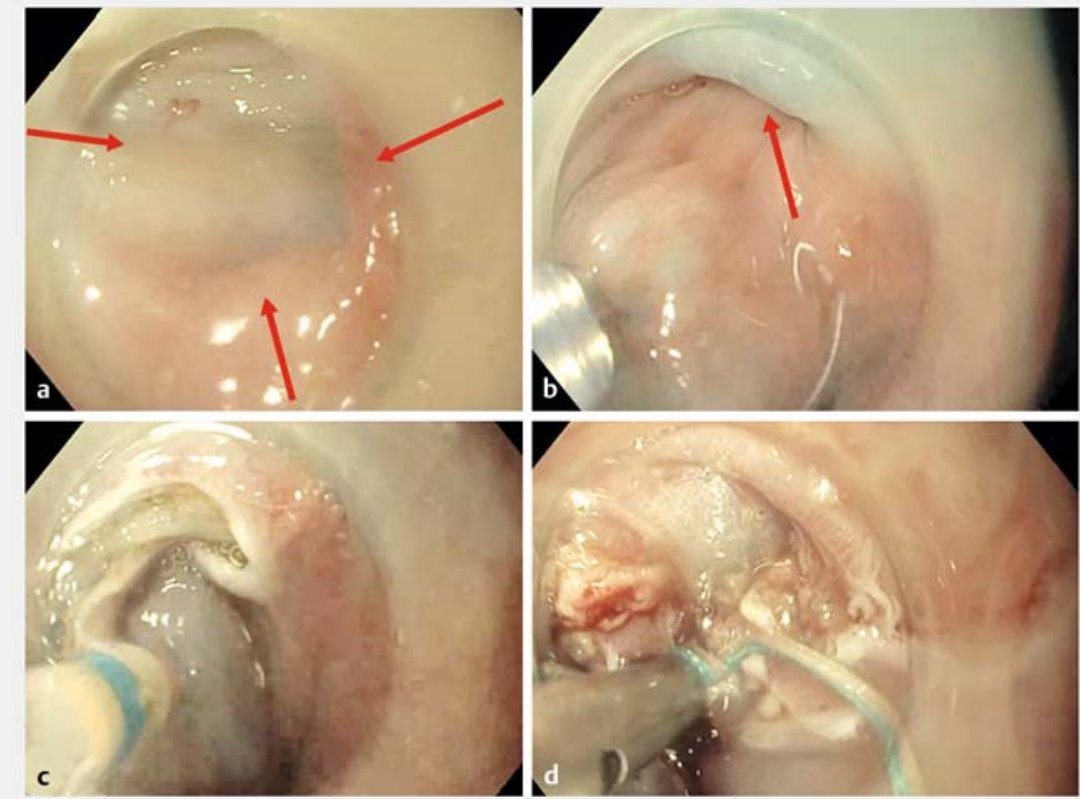

- Fig. 1 Endoscopic submucosal dissection (ESD) with clip-and-line traction of the fistula tract. a Aspect of the large fistula before ESD (red arrows showing the fistula orifice). $\mathbf{b}$ Injection of the submucosa around the fistula orifice. $\mathrm{c}$ Incision and ESD of the surrounding mucosa. $\mathbf{d}$ Clip-and-line traction of the mucosa covering the fistula tract for deeper removal.

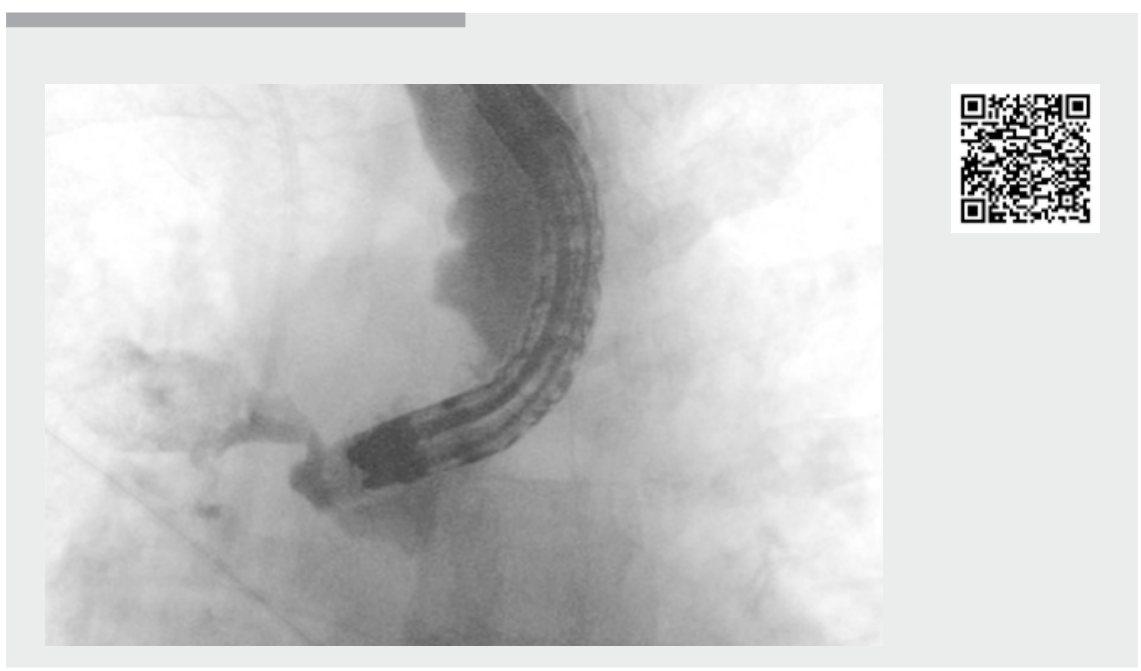

Video 1 Endoscopic submucosal dissection with clip-and-line traction of a refractory esophagopleural fistula following lobectomy. 

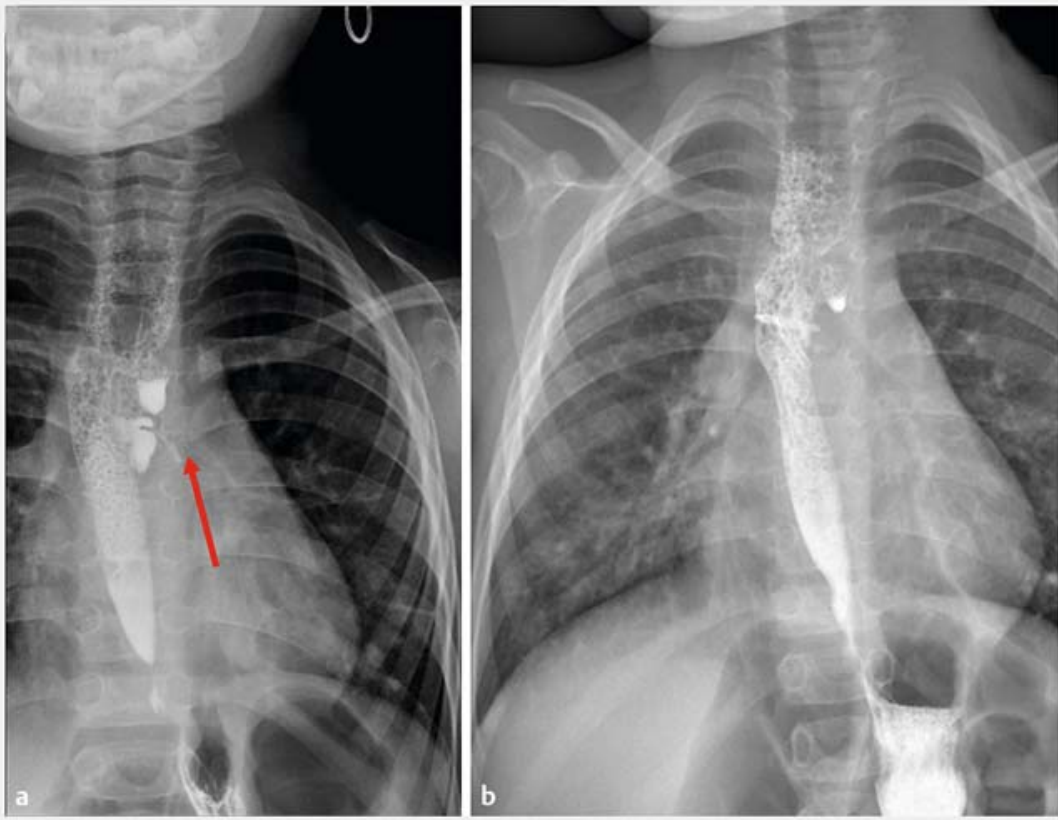

- Fig. 2 Radiologic aspect of the fistula before and after treatment with opacification. a Opacification before closure (red arrow showing the fistula tract). b Aspect after closure.

place remains to be defined in the therapeutic strategy by prospective studies.

Endoscopy_UCTN_Code_TTT_1AO_2AI

\section{Competing interests}

The authors declare that they have no conflict of interest.

The authors

\section{Florian Béoletto ${ }^{1}$, Florian Rostain ${ }^{1}$, Adriane} Lesne $^{1,2}$, Gaëtanne Roquet ${ }^{3}$, Nada Nargues ${ }^{4}$, Olivier Ragi ${ }^{1}$, Mathieu Pioche ${ }^{1}$

1 Department of Endoscopy and Gastroenterology, Pavillon L, Edouard Herriot Hospital, Lyon, France

2 Department of Gastroenterology, Clinique de la Sauvegarde, Lyon, France

3 Department of Thoracic Surgery, Clinique de la Sauvegarde, Lyon, France

4 Department of Anesthesiology, Edouard Herriot Hospital, Lyon, France

\section{Corresponding author}

\section{Mathieu Pioche, MD}

Endoscopy Unit - Digestive Disease Department, Pavillon L - Edouard Herriot Hospital, 69437 Lyon Cédex, France Fax: +33-4-72-11-01-47

mathieu.pioche@chu-lyon.fr

\section{References}

[1] Lauwers GY, Ban S, Mino M et al. Endoscopic mucosal resection for gastric epithelial neoplasms: a study of 39 cases with emphasis on the evaluation of specimens and recommendations for optimal pathologic analysis. Mod Pathol 2004; 17: 2-8

[2] Inoue M, Nakanishi R, Osaki T et al. Esophagopleural fistula originating from diverticulum after pneumonectomy. A case report and review of the literature. J Cardiovasc Surg (Torino) 1999; 40: 761-763

[3] Yamaguchi A, Moro H, lizuka M et al. [Postpneumonectomy esophagopleural fistulasuccessful one-stage repair with omental flap and thoracoplasty]. Nihon Kyobu Geka Gakkai Zasshi 1989; 37: 2202-2206

[4] Guturu P, Bilal M, Rangasetty U et al. Endoscopic closure of esophagopleural fistula with Amplatzer atrial septal defect closure device. Am J Gastroenterol 2019; 114: 198

[5] Ciochina M, Cruceru M, Rivory J et al. Esophagobronchial fistula after sleeve gastrectomy successfully treated by endoscopic submucosal dissection and over-the-scope clip. Endoscopy 2019. doi:10.1055/a-10114092

\section{Bibliography}

Endoscopy 2021; 53: E138-E139

DOI 10.1055/a-1216-0993

ISSN 0013-726X

published online 5.8 .2020

(c) 2020. Thieme. All rights reserved.

Georg Thieme Verlag KG, Rüdigerstraße 14, 70469 Stuttgart, Germany

\section{ENDOSCOPY E-VIDEOS}

https://eref.thieme.de/e-videos

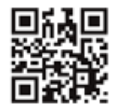

Endoscopy E-Videos is a free access online section, reporting on interesting cases and new

techniques in gastroenterological endoscopy. All papers include a high quality video and all contributions are freely accessible online.

This section has its own submission website at https://mc.manuscriptcentral.com/e-videos 